\title{
Studies on the Synthesis of Silica Powder from Rice Husk Ash as Reinforcement Filler in Rubber Tire Tread Part: Replacement of Commercial Precipitated Silica
}

\author{
Addis Lemessa Jembere*, Solomon Workneh Fanta \\ Bahir Dar Institute of Technology, Bahir Dar University, Bahir Dar, Ethiopia \\ Email address: \\ addislemessa@gmail.com (A. L. Jembere), solworkneh@gmail.com (S. W. Fanta) \\ *Corresponding author
}

\section{To cite this article:}

Addis Lemessa Jembere, Solomon Workneh Fanta. Studies on the Synthesis of Silica Powder from Rice Husk Ash as Reinforcement Filler in Rubber Tire Tread Part: Replacement of Commercial Precipitated Silica. International Journal of Materials Science and Applications.

Vol. 6, No. 1, 2017, pp. 37-44. doi: 10.11648/j.ijmsa.20170601.16

Received: November 30, 2016; Accepted: January 16, 2017; Published: January 18, 2017

\begin{abstract}
Rice husks, which can be considered as an agricultural waste, are produced every year in South Gonder, Ethiopia. Precipitated silica is commonly used as reinforcing filler in rubber industry, in the present study an effort has been attempted to replace commercial silica commonly used in natural rubber industries with rice husk ash silica (RHAS). Silica was extracted from RHA by using alkaline extraction followed by acid precipitation. The synthesized RHAS was characterized by AAS, BET, DSC, FTIR, and XRD. RHAS was then used as reinforcing filler in natural rubber. The curing characteristics of natural rubber products filled with RHAS resulted a smaller scorch time which caused a premature vulcanization than the commercial silica filled rubber composite. Overall mechanical properties like hardness, young's modulus, abrasion resistance of rubber products reinforced with RHAS was better than commercial silica filled rubber composite.
\end{abstract}

Keywords: RHAS, RHA, Scorch Time, Composite, Reinforcement

\section{Introduction}

Amorphous silica and carbon black have been used as reinforcing fillers in the rubber industry for decades. Their presence in rubber is essential to achieve longer-wearing products, increased tire strength and longevity. The world production of amorphous precipitated silica is 1.3 million tons of which one-third is used in tire production [1]. Silica has been used in the treads of tires for more than twenty years in order to reduce the fuel consumption of vehicles, thus contributing to a reduction in vehicle emissions of greenhouse gases [2].

Rice is one of the most important cereal crops cultivated in sub-Saharan Africa. Currently, rice is grown in over $75 \%$ of the African countries with a total population of 800 million people. In Ethiopia, rice is a recently introduced crop and its area and production have been increasing [3]. According to the report by Ministry of agriculture, in 2010 the potential rice production area in Ethiopia is estimated to be about seventeen million hectare[4], Although RH has been already employed in different fields as a material for animal husbandry, it is still often considered as a waste product of rice milling, and thus, often dumped on wasteland. Furthermore, it is well-known that $\mathrm{RH}$ can be also used as a renewable fuel in cogenerating plants, considering its high calorific value (4012 $\mathrm{Kcal} \mathrm{kg}^{-1}$ ) [5]. Indeed, during its combustion, about 20-25 wt\% of rice husk ash (RHA), containing more than $90 \%$ silica, with traces of other metal oxides, is produced [6]. Rice husk which is discarded as an agricultural waste is rich in silica can be economically viable raw material for extraction silica. Making use of this huge potential as reinforcement filler in rubber can offer a number of advantages in heat resistance, high modulus, and hardness, tear strength, abrasion resistance, improve rolling resistance, reduction in heat buildup, rapture resistance etc. the objective of these study was (1) To characterize extracted silica using AAS, FTIR, XRD and DSC. (2) To evaluate the performance of RHAS as compared to commercially available silica in terms of their mechanical property and rheological property. 


\section{Materials and Methods}

\subsection{Materials}

Rice husk as a source of precipitated silica was brought from local rice producers and millers located around Woreta, South Gonder, Ethiopia, where there is a high production of rice compared to the other part of Ethiopia.

\subsection{Methods}

Silica was extracted from RHA using a simple alkaline extraction [7]. RH was burned at $700^{\circ} \mathrm{C}$ for 2 hours using Muffle furnace. $10 \mathrm{~g}$ of RHA was dispersed at $60 \mathrm{ml}$ of distilled water at $60^{\circ} \mathrm{C}, 2.5 \mathrm{M}$ of $\mathrm{NaOH}$ for one and half hour. Silica content of the RHA leached out to the aqueous phase of the dispersion in the form of soluble sodium silicate according to the following reaction.

$$
\mathrm{SiO}_{2}(\text { Ash })+2 \mathrm{NaOH}=\mathrm{Na}_{2} \mathrm{SiO}_{3}+\mathrm{H}_{2}
$$

The resulting sodium silicate solution was filtered using $110 \mathrm{~mm}$ ash less filter paper in a vacuumed filtration condition. The carbon residues were washed with $100 \mathrm{ml}$ of boiling water. The filtrates and washings were allowed to cool to room temperature and then acidified with 2 Normal sulfuric acid, which precipitated the dissolved silicate in the form of white gelatinous solid $\left(\mathrm{SiO}_{2}\right)$ with constant stirring to $\mathrm{pH}$ 7. The precipitation using $\mathrm{H}_{2} \mathrm{SO}_{4}$ occurred according to the following reaction.

$$
\mathrm{Na}_{2} \mathrm{SiO}_{3}+\mathrm{H}_{2} \mathrm{SO}_{4}=\mathrm{SiO}_{2}+\mathrm{Na}_{2} \mathrm{SO}_{4}+\mathrm{H}_{2} \mathrm{O}
$$

Silica gels started to precipitate when the $\mathrm{pH}$ decreased to less than 10 followed by aging for $18 \mathrm{~h}$. The gels were then dried at $80^{\circ} \mathrm{C}$ for $12 \mathrm{~h}$ to produce xerogels finally samples were ground in to powder by using mortal and piston and stored in airtight plastic bags.

\subsubsection{Characterization of Extracted Silica}

Chemical content analysis

In this analysis atomic absorption spectrophotometer (AAS) was used to characterize the chemical constituents of RHAS, including major and minor oxides. These analyses were conducted in geochemical laboratory, Ethiopian geological survey.

BET surface area analysis

Surface area of particles of RHAS was measured using BET method. The measurements of specific surface area were performed at various partial pressures using NOVA 4000e, Surface area and pore size Analyzer Quantachrome technology, in Bahir Dar institute of technology. Measurements were carried out under nitrogen adsorption at liquid nitrogen temperature, the data calculated were based on nitrogen desorption isotherm at liquid nitrogen temperatures and the software provided by NOVA.

Fourier Transform Spectroscopy (FTIR)

The FTIR spectra were recorded for qualitative characterization of surface functional groups. Functional groups present in RHAS were confirmed using Fourier
Transform Infrared (FTIR) using $\mathrm{KBr}$ pellet technique on JASCO model 4100. This analysis was conducted in AAU (Addis Ababa University), Department of chemistry.

X-Ray Diffraction (XRD)

$\mathrm{XRD}$ analysis was conducted in Material engineering department, Adama Science and Technology University. Xray 7000 diffractometer SHIMADZU Corporation (Kyoto, Japan) were used to study the phase nature of the silica extracted from RHA. The rice husk ash samples (obtained from alkaline extraction experiments) were subjected to XRay Diffraction analysis.

The ground samples were analyzed by $\mathrm{Cu}$ radiation with a scanning rate of $2^{\circ}$ per minutes and scan range 10.000 80.000 and using an acceleration voltage of $40 \mathrm{kV}$ and current of $30 \mathrm{~mA}$. Average particle size had been estimated by using Debye-Scherrer formula.

Differential spectra calorimetric (DSC)

DSC 8000 (Differential Scanning Calorimetry) was used to study the thermal stability of the silica, this instrumental techique were conducted in chemical engineering research grade laboratory, Bahir Dar institute of Technology (BIT).

\subsubsection{Rubber Compounding}

Reinforcing of filler in to rubber and all aspects of the testing were conducted in Horizon Addis Tire factory, Addis Ababa, Ethiopia. The mixing was done as per ASTM D-3185 (2006) on two roll laboratory size mixing mill (150mm* $300 \mathrm{~mm}$ ). Table (1) shows compounding with 12 PHR (parts per hundred) silica filler were used consisting of three mixing runs rubber formulation.

Table 1. Rubber compounding formulation.

\begin{tabular}{llll}
\hline Ingredients & $\begin{array}{l}\text { Mix A } \\
\text { (PHR) }\end{array}$ & $\begin{array}{l}\text { Mix B } \\
\text { (PHR) }\end{array}$ & $\begin{array}{l}\text { Mix C } \\
\text { (PHR) }\end{array}$ \\
\hline SMR-20 & 70 & 70 & 70 \\
HIGH CIS BR-1220 & 30 & 30 & 30 \\
N-220 / ISAF & 45 & 45 & 45 \\
DUTREX & 10 & 10 & 10 \\
ZINC OXIDE (98\%) & 5 & 5 & 5 \\
RENACIT PEPTIZER / ZINCOLET-86 & 0.1 & 0.1 & 0.1 \\
ACTIPLAST /ZINCOLET-T/ACMETOL T & 1.5 & 1.5 & 1.5 \\
RUBBER GRADE (STERIC ACID 1600) & 3 & 3 & 3 \\
6PPD & 3 & 3 & 3 \\
TMQ & 0.75 & 0.75 & 0.75 \\
ANTILUX /OSW & 1 & 1 & 1 \\
PERKASIL KS 408/ACTIVE SILICA & 12 & 0 & 0 \\
RHAS & 0 & 12 & 0 \\
TBBS & 1.1 & 1.1 & 1.1 \\
NORMAL SULPHER & 1.5 & 1.5 & 1.5 \\
TOTAL & 183.95 & 183.95 & 171.95 \\
\hline
\end{tabular}

\subsubsection{Curing and Molding}

Vulcanization of various test samples was carried out in an electrically heated hydraulic press having $150 \mathrm{~mm} * 150 \mathrm{~mm}$ platen at $150^{\circ} \mathrm{C}$ at a pressure of $200 \mathrm{~kg} / \mathrm{cm}^{2}$ on the mould up to optimum cure time of $30 \mathrm{~min}$. Cure characteristics of the mixes were determined as per ASTM D3182 (2007) using oscillating Reo-line, moving die (Prescott instrument technology).

Specific gravity 
Prior to vulcanization specific gravity of the compounded rubber was measured using specific gravity taster (Elatest brabender Technology, Germany).

Moony viscosity

According to ASTM D1646 (2004) the Compounded rubber fill (RHAS, COS and unfilled) were tested prior to curing or vulcanization. Samples for Mooney viscosity were cut from raw natural rubber strips with thickness about $1 \mathrm{~cm}$, and diameter of $4.5 \mathrm{~cm}$ at $100^{\circ} \mathrm{C}$ on Mooney viscometer (Prescott instrument technology) with large rotor. Preheat time $1 \mathrm{~min}$ with test time $4 \mathrm{~min}$ were applied and values of Mooney viscosity ML (1+4) $100^{\circ}$ were obtained for the three samples separately.

\section{Curing characteristics}

Curing characteristics was studied using reo-line, moving die to study the cross linking density of the rubber matrix with the RHAS filler. Sample of $5 \mathrm{~g}$ of compounded rubber composite was placed in the lower die that is oscillating through a small deformation angle of arc $\left(0.5^{\circ}\right)$ at a frequency of $50 \mathrm{cpm}$ (cycle per minute) and at a temperature of $175^{\circ} \mathrm{C}$. The torque transducer on the upper die senses the forces being transmitted through the rubber. The torque is plotted as a function of time and the curve is called a cure graph or Rheogrhaph. The important data that could be taken from the torque-time curve are initial torque ( $\mathrm{S}$ ' initial), minimum torque ( $\mathrm{S}^{\prime}$ minimum), maximum torque ( $\mathrm{S}^{\prime}$ maximum), Final torque( $S^{\prime}$ final), starting point for vulcanization (TS1), scorch time (T'10) and optimum cure time (T'90).

Stress-strain properties

Stress-strain tests includes Modulus, tensile strength, load at break and elongation at break, these tests were carried out as per ASTM D412-06 using dumbbell specimens on Tensometeric machine. The measurement was recorded as Mpa.

\section{Tear strength}

Tear resistance of the sample was tested as per ASTM D 624-00. A tearing strain (and stress) was applied to un-nicked $90^{\circ}$ angle test specimens by means of a tensile testing machine called tensometer. The measured sample was recorded in $\mathrm{Kgf}$ (kilio gram force).

\section{Hardness}

The testing was done as per ASTM D 2240-05 using shore A type Dorometer. The type of specimen was based on micro taster having thickness of $2.2 \mathrm{~mm}$. Readings were taken after 15 seconds of the indentation when firm contact has been established with the specimens. The result was recorded in shore A.

Abrasion resistances

The abrasion resistance of the samples was studied with a DIN Abrader as per ASTM D 5963-04. The abrasion loss was calculated using:

Abrasion loss $=($ weight loss/initial weight $) * 100$

Ten runs for each category of rubbers specimens were tested. (I.e. test runs for RHAS, COS and unfilled) The results were expressed as the mean value.

\section{Result and discussion}

Figure (1) shows the physical appearance of extracted silica granules from rice husk ash. White silica was obtained as a result of the alkaline extraction with minimal impurities at the intermediate process. Small amount of carbonous constitute from rice husk ash were noticed visually which give rise to the formation of small impurities at the end product. Different characterization techniques were employed to study the compatibility of extracted RHAS as filler in rubber.

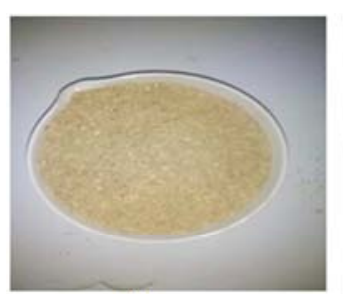

(a)

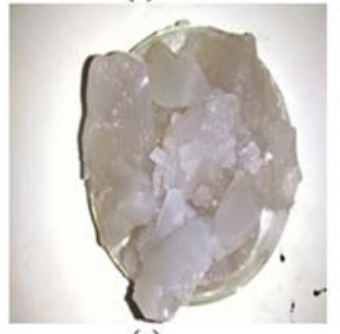

(c)

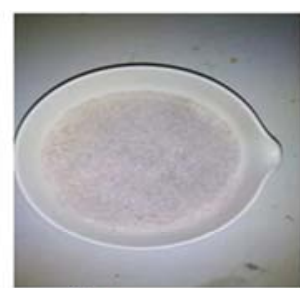

(b)

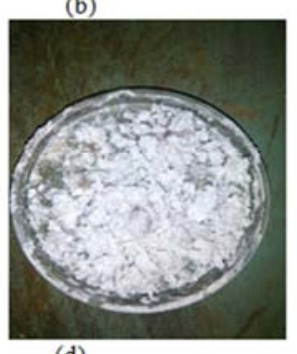

(d)
Figure 1. (a) as received $R H$, (b) burned $R H$, (c) silica gel (d) silica powder granules.

\subsection{Characterization of Extracted Silica}

\subsubsection{Chemical Compositions of the RHAS}

Table (2) shows the major and minor mineral oxide of the RHAS sample, based on the result reveled by AAS the major constituent of RHAS was $\mathrm{SiO}_{2}$. Small amounts of $\mathrm{K}_{2} \mathrm{O}$, $\mathrm{Al}_{2} \mathrm{O}_{3}, \mathrm{Fe}_{2} \mathrm{O}_{3}, \mathrm{CaO}, \mathrm{MgO}$ and $\mathrm{Na}_{2} \mathrm{O}$ were also present, along with traces of $\mathrm{MnO}, \mathrm{H}_{2} \mathrm{O}, \mathrm{TiO}_{2}$ and $\mathrm{P}_{2} \mathrm{O}_{5}$. It is evident from the results that chemically RHAS composed of silicon compounds in large amounts. The measured values of rice husk ash composition are very much within the ranges reported in the literature. Silica content in RHA is generally more than $80-85 \%$ [8].

Table 2. chemical composition of RHAS.

\begin{tabular}{ll}
\hline Constituents & Constituents (\%) \\
\hline $\mathrm{SiO}_{2}$ & 83.7 \\
$\mathrm{Al}_{2} \mathrm{O}_{3}$ & 1.87 \\
$\mathrm{Fe}_{2} \mathrm{O}_{3}$ & 1.36 \\
$\mathrm{CaO}$ & 1.00 \\
$\mathrm{MgO}$ & 2.62 \\
$\mathrm{Na}$ & $\mathrm{O}$ \\
$\mathrm{K}_{2} \mathrm{O}$ & 0.44 \\
$\mathrm{MnO}$ & 5.42 \\
$\mathrm{P}_{2} \mathrm{O}_{5}$ & 0.14 \\
$\mathrm{TiO}_{2}$ & 0.65 \\
$\mathrm{H}_{2} \mathrm{O}$ & $<0.01$ \\
$\mathrm{LOI}^{*}$ & 0.77 \\
\hline
\end{tabular}

* Loss on ignition 


\subsubsection{BET Surface Area Analysis}

The BET surface area of RHAS and COS are given in Table (3). Surface area of RHAS is found to be lower than that of commercial silica; In general, material with a higher surface area implies a higher dispersion. However, the surface activity also plays important role in the rubber reinforcement.

Table 3. BET surface area for RHAS and COS.

\begin{tabular}{ll}
\hline Silica type & Surface $\operatorname{Area}\left(\mathbf{m}^{2} / \mathbf{g}\right)$ \\
\hline RHAS & 25.778 \\
COS & 37.570 \\
\hline
\end{tabular}

\subsubsection{Fourier Transform Spectroscopy (FTIR)}

The major chemical groups present in silica are identified by the FTIR spectra shown in Figure (2). The broad band between 2800 and $3750 \mathrm{~cm}^{-1}$ was due to silanol hydroxyl groups and adsorbed water. peak between 1200 and $1050 \mathrm{~cm}^{-}$ ${ }^{1}$ is associated with the $\mathrm{Si}-\mathrm{O}-\mathrm{Si}$ asymmetric band stretching and $790 \mathrm{~cm}^{-1}$ to $815 \mathrm{~cm}^{-1}$ belongs to Si-O-Si stretching modes The peak in the range of $470-450 \mathrm{~cm}^{-1}$ is attributed to the asymmetric bending vibration [7]. The FTIR analysis achieved here in this experiment is similar to those reported by other workers who carried out similar studies [9]. From figure 2(b) we can observe that intensity of most peaks is small for RHA, while it increases in the case of RHAS shows maximum broad peak. It shows a sharper pick in the case of RHAS curve, this indicates that silica content would vary by method of treatment and reflects the highest purity in RHAS.

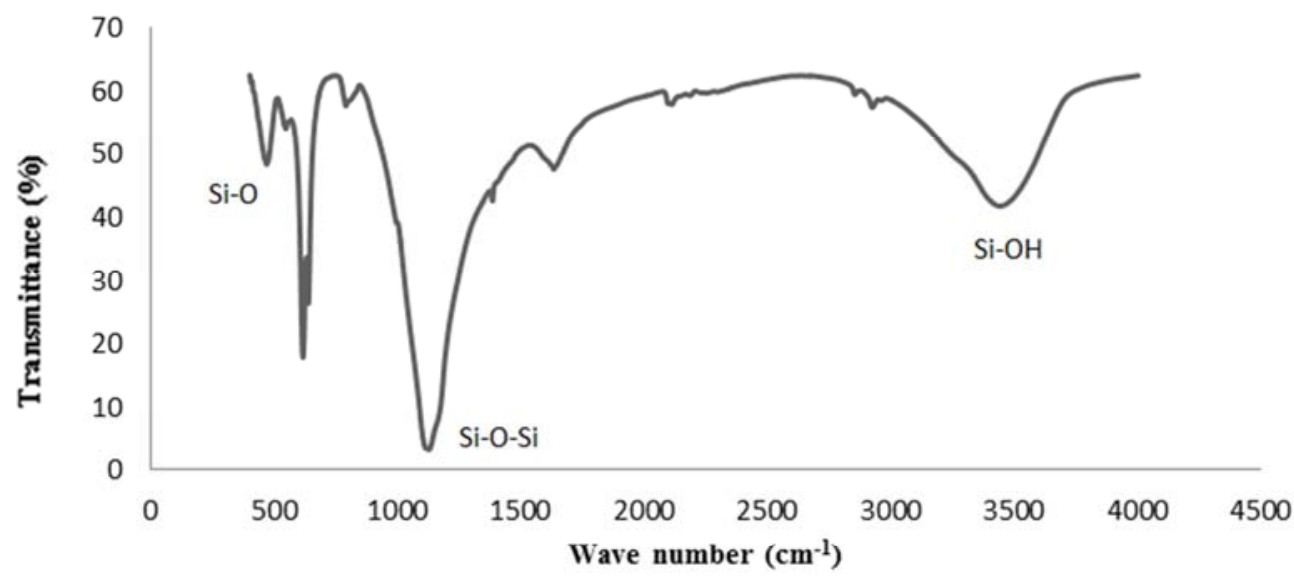

(a)

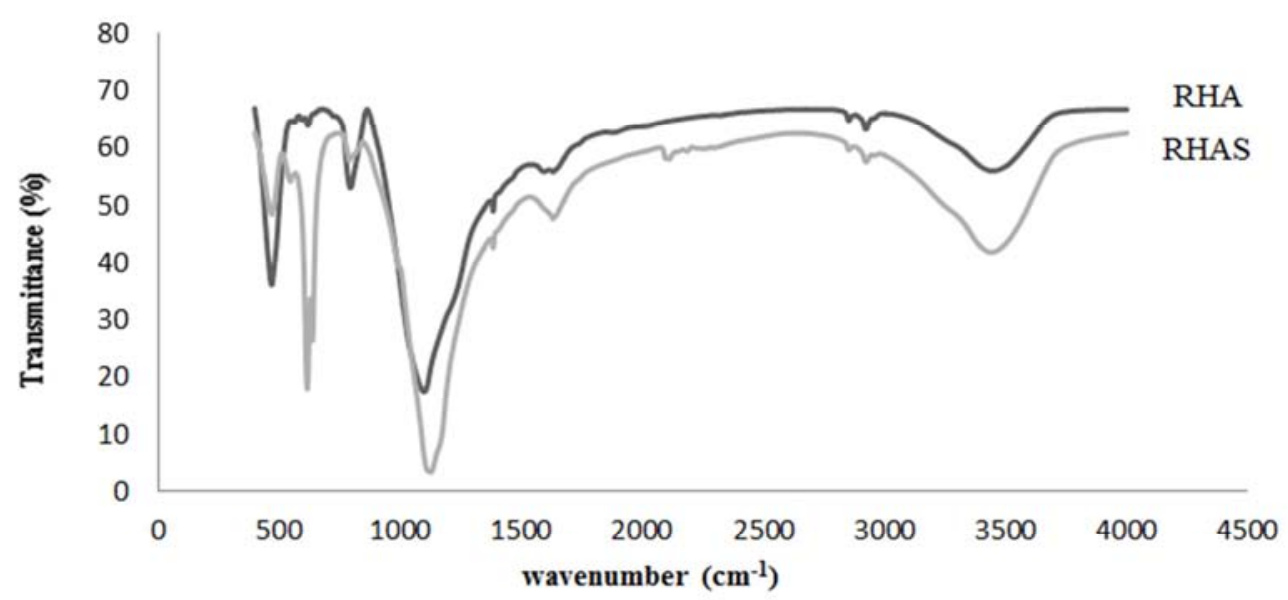

(b)

Figure 2. FTIR spectra for (a) RHAS (b) RHAS and RHA.

\subsubsection{Differential Scanning Calorimetric (DSC)}

Figure (3) shows thermal stability of the RHA and RHAS, from this analysis DSC revels the melting point (Tm) of RHA and RHAS, based on this it was observed that RHA and RHAS shows a major peaks at $462.31^{\circ} \mathrm{C}$ and $499.7^{\circ} \mathrm{C}$ respectively. The Tm for RHAS was higher than that RHA, Though there are miner picks in the RHAS that shows the melting down of some impurities left over during the extruction. Two enthalpy changes were observed for RHAS at $215^{\circ} \mathrm{C}$ and $250^{\circ} \mathrm{C}$, corresponding to heat absorption due to the loss of organic material from the sample. This analysis is important to investigate the degree of how RHAS withstand the temprature of volcanization during curing process of rubber. 


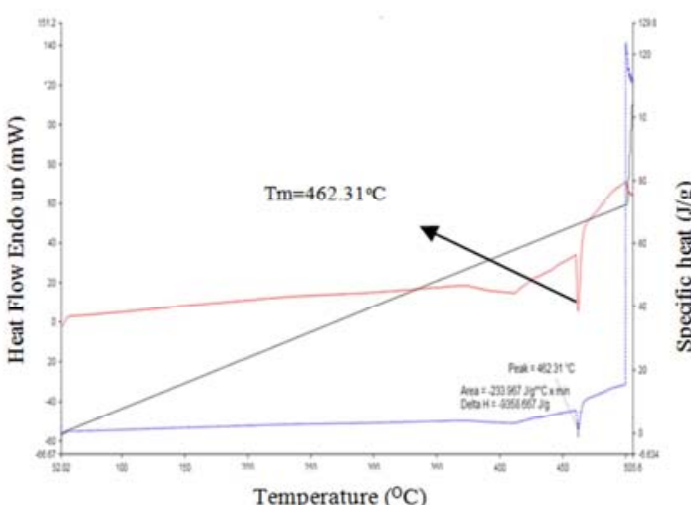

(a)

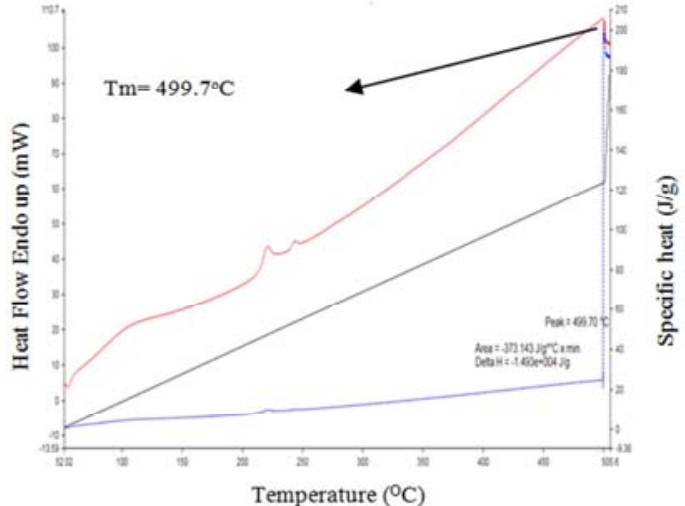

(b)

Heat Flow endo up (mW) Specific heat $(\mathrm{J} / \mathrm{g} \circ \mathrm{C})$

Figure 3. Differential scanning chalorimetry (DSC) curve for (a) RHA and (b) RHAS

\subsubsection{X-Ray Diffraction (XRD)}

The XRD pattern of the RHAS in Figure (4) shows that sharper strong broad peaks were observed at $2 \theta=32.1143$, 19.0442 and 33.8315 was observed. Amorphous to crystalline transformation was clearly identified. The major reflections occur at $2 \theta$ angles of $32.1143^{\circ}$ which corresponds to a crystalline structure and the second major pick which is
$2 \theta=19^{\circ}$ represent higher concentration of amorphous silica. Also broad peak spanning $2 \theta$ angle at $23^{0} 28^{0}, 23^{0}, 33^{\circ}$ which is characteristic of amorphous structures is observed [10,11]. Particle size of the RHAS was calculated using DebyeScherrer formula, that the particle size for the RHAS is represented by the major peak i.e. $2 \theta$ at 32.1143 which the particle size gives $0.33 \mathrm{~nm}$.

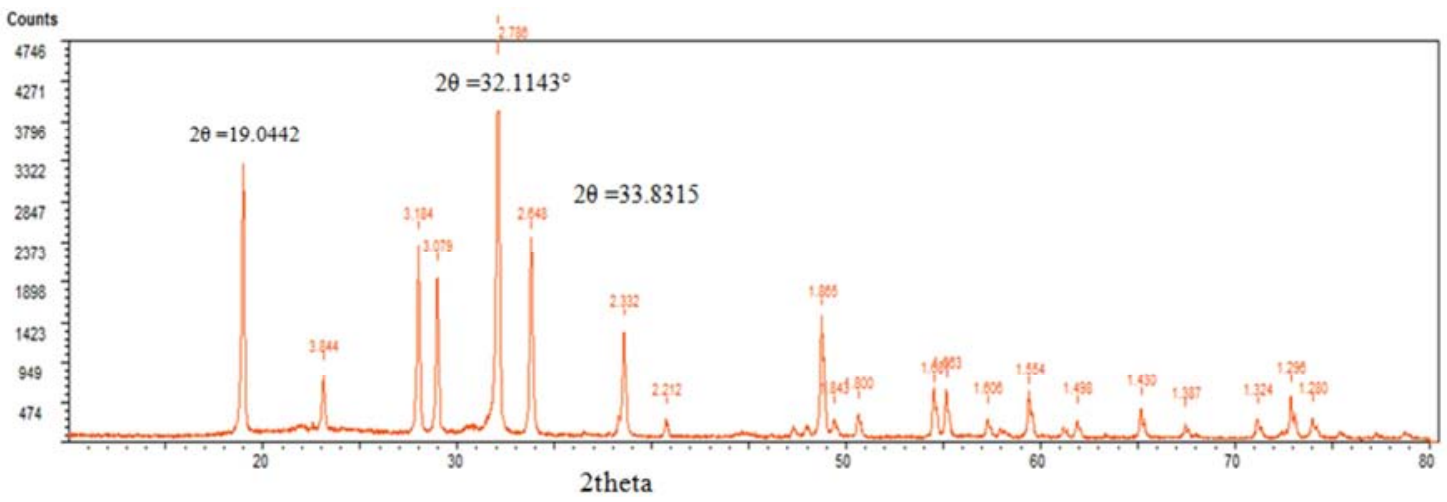

Figure 4. X-Ray Diffraction(XRD) plot of silica produced from rice husk Ash.

\subsection{Mechanical and Rheological Properties of Compound Rubber Composites}

\subsubsection{Rheological Properties}

From the result presented in Table (4) effect of RHAS filler loading into rubber composite matrix has been clearly shown in compression with COS and silica unfilled rubber product. The scorch time of products reinforced with RHA silica was lower than COS reinforced. In other word the RHAS compound has a tendency to scorch prematurely before reaching all extremities of mould cavities and this also indicate premature formation of crosslink network rendering the compound elastic, in the case COS composite, had an ability to absorb activators used in the compound thus prolonging the scorch time, The other important characteristics that could be noted is optimum cure time, which is time required for reaching $90 \%$ of the maximum achievable torque or network density.
Table 4. Overall rheological and mechanical properties of RHAS, COS and unfilled rubber composite.

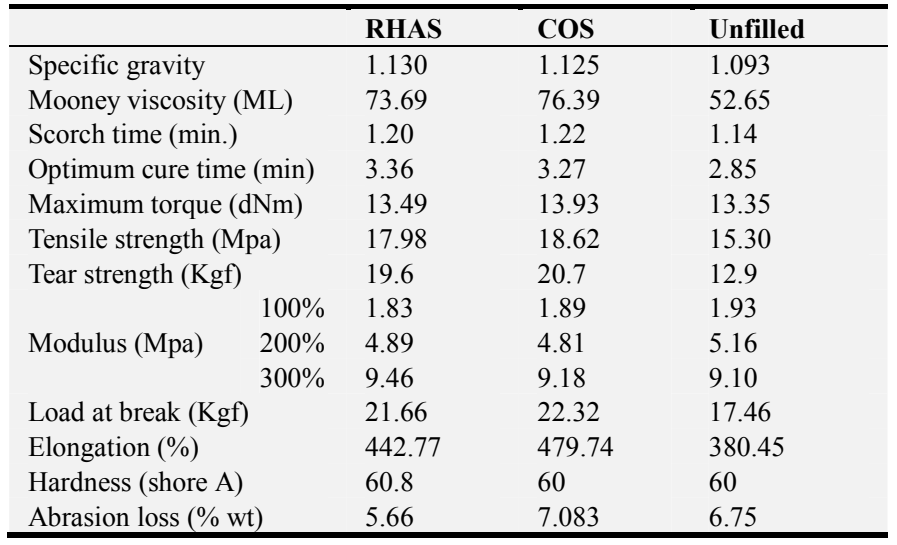

At the given temperature i.e. $175^{\circ} \mathrm{C}$, the optimum cure 
time (T'90) for RHAS is higher, then followed by COS and unreinforced rubber product. The reason for the delayed of cure reaction in the case of RHAS may be attributed due to the possible interaction of the silica with the accelerators making it unavailable for cure reaction. This is commonly explained by the silica structure, which can absorb some accelerators into the porous structure, thus slowing down the vulcanization process. Rheograph in Figure (5) shows the differential torque as a function of time applied on the RHAS filled rubber composite, The maximum torque for the RHAS was $13.49 \mathrm{~d}$. Nm which is lower than the COS rubber composite. Rubber product reinforced with RHAS composite shows a higher differential torque than the unreinforced rubber product, the differential torque is superior in the case of COS reinforced rubber compound. The Differential torque is a measure of crosslink density and stiffness in the rubber. This increase in torque is due to the presence of silica rubber crosslink that imparts more restriction to deformation.

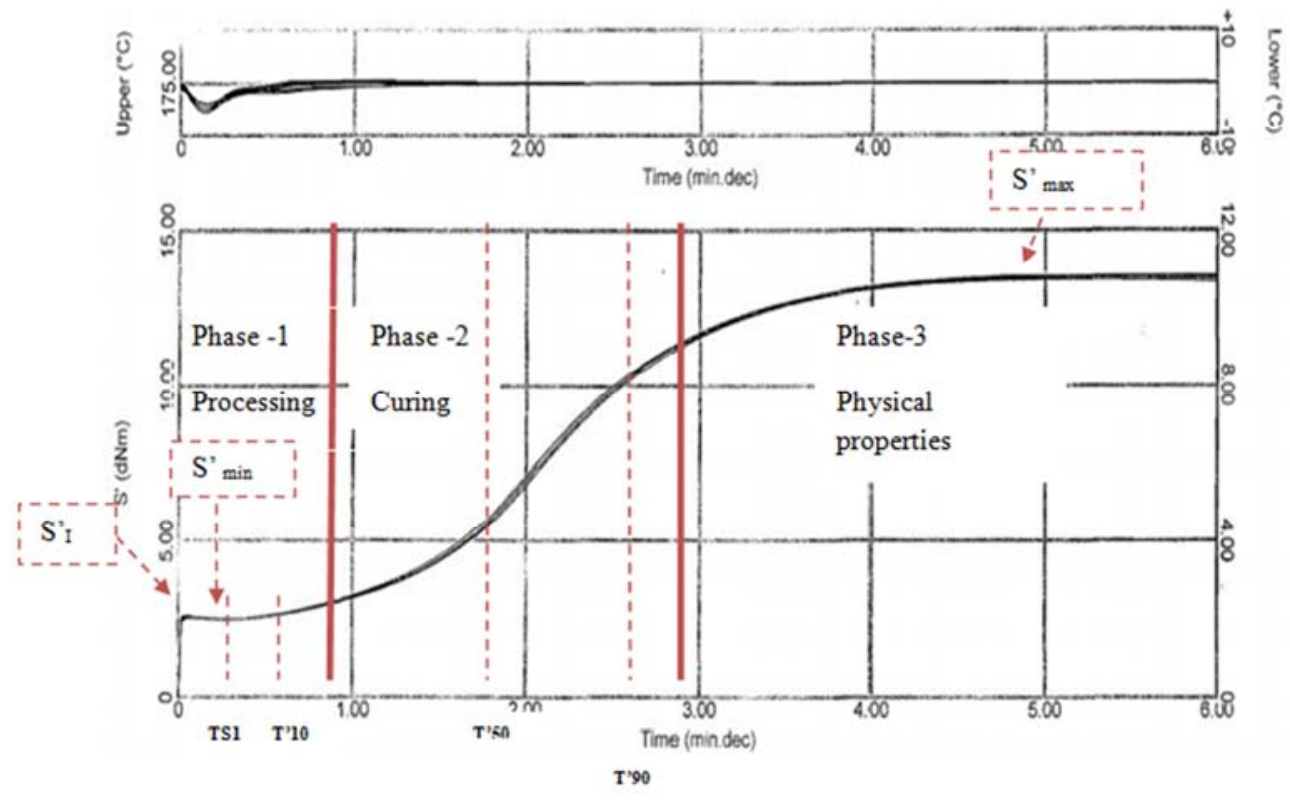

Figure 5. Rheograph for the RHAS rubber composite.

Table 5. Variation of torque, cure time and scorch time of the composites of COS, RHAS and unreinforced rubber products.

\begin{tabular}{lllllll}
\hline Filler type & S'm(Minimum torque) & $\begin{array}{l}\text { S'max(maximum } \\
\text { torque) }\end{array}$ & S'f (final torque) & TS1 & T'10( scorch time) & T'90 (optimum cure time) \\
\hline COS & 1.98 & 13.93 & 13.89 & 1.12 & 1.22 \\
RHAS & 2.50 & 13.49 & 13.44 & 1.16 & 1.20 \\
Unfilled & 1.97 & 13.35 & 13.14 & 1.08 & 1.14 & 3.27 \\
\hline
\end{tabular}

\subsubsection{Mechanical Properties}

The products reinforced with COS had a higher tensile strength followed by RHAS and unreinforced rubber products respectively. It is believed that a smaller particle size and uniform dispersion of both COS and RHAS in natural rubber materials contribute to better tensile strength, however tensile strength is higher in the case of COS reinforced rubber product, surface area for the RHAS is lower than the COS, this attributed a lower tensile strength. In addition, the nature of the RHAS filler, given by the presence of both silica and other components, with different physical and chemical properties, may also reduce the efficiency of this filler in strengthening the rubber matrix relative to COS. In addition study reported that In the case of the incorporation of RHA into polypropylene/natural rubber blend, agglomeration of the RHA within the blend at the inter phase aggravates the situation, which accounts for the reduction in tensile strength [12].

Similar to tensile strength, the addition of the fillers somewhat reduced the tear strength of the vulcanisate. Tear strength, like tensile strength, is affected by filler particle size and surface area. Unreinforced rubber exhibits lower tear strength, because silica filler attributed to the reduction of stress concentration at the crack tips, particularly the fineparticle ones.

Despite having silica content comparable to that of commercial silica, the RHAS filled vulcanizates are not as tear-resistant as are those containing the commercial product. Therefore, the different performances may be the result of a much more significant influence of the nature of the surface, particle size, and surface area of the filler used.

Modulus is an indication of the relative stiffness of the material. Table (4) shows the effect of filler loading on modulus at $100 \%, 200 \%$ and $300 \%$ elongation of the rubber materials. It can be seen that RHAS improves the stiffness of natural rubber materials, whereas COS and unreinforced show a lesser effect. The higher effect on RHAS may be attributed to the good rubber-filler interaction of this filler. It can be observed that, the COS-filled compound has higher tensile 
strength and tear strength, whereas its modulus is lower than that of RHAS-filled rubber materials. Surface area is the most important factor controlling the tensile strength, whereas the surface activity (rubber-filler interaction) controls the modulus [13]. The higher Young modulus of the composites filled with RHAS compared to those filled with COS could be explained with the stronger restriction of the mobility and deformation of the matrix, modulus of RHAS is found to be higher, so the movement of polymer molecule is difficult. The higher stiffness of RHAS composite is due to high modulus of the RHAS filler that minimize the elongation at break and fracture become brittle (lower load at break).

The load at break for the three composites test samples were given, based on the result COS composites shows a maximum result followed by RHAS and unreinforced composites. load at break characterstics also can be explained in terms of surface area, since RHAS has lower surface area than COS, the dispersion of the filler in the rubber will be poor, this would result in formation of certain cracks in the rubber matrix, therefore when load is applied the creack initiation will result in breakage of the rubber. However comparatively the diffrence in load at break between the RHAS and COS is not as such significant.

It has been seen in the result that there is significant difference in the elongation at break of the test samples, COS resulted a high elongation followed by RHAS and unreinforced rubber composite. Based on studies due to the addition of RHAS the movement and displacement of the polymer chains are restricted most importantly the rigid nature of the RHAS filler is due to the higher silica content in the ash and the rigidity of the RHA filler also improved the stiffness and rigidity of the composite system [14].

RHAS filled rubber shows a maximum hardness followed by $\operatorname{COS}$ and unreinforced product, especially when the particle sizes of the fillers are large. Large filler particles obstruct the movement of the rubber matrix when the matrix is subjected to indentation. Consequently, indentation hardness is increased [15]. In addition, high specific gravity of RHAS rubber composite accounts for a better hardness, hardness also can be related to the differential torque, the hardness values are seen to correspond to the torque difference values.

The abrasion resistance of a solid body is defined as its ability to withstand the progressive removal of material from its surface as a result of mechanical action of a rubbing, scraping, or erosive nature. one can observe that abrasion resistance obtained from unreinforced composite is lower than the corresponding value for RHAS and COS composites. the abrasion resistance of filled rubber is basically determined by filler characterization, especially its morphology and surface reactivity. The lower filler- filler interaction leads to higher abrasion resistance. Therefore, addition of RHA in the rubber hybrid composites minimizes the filler-filler interaction. Two important factors in studying abrasion behaviors of rubbers are modulus and crosslink density. High modulus and crosslink density lead to the enhancement of abrasion strength of rubber compounds. Due to this reason RHAS filled rubber composite has a better abrasion resistance. studies reported that the abrasion resistance of vulcanisates was contingent upon their hardness and cross-link density [16].

\section{Conclusion}

Generally, the possibility of using rice husk ash silica (RHAS) as alternative filler for natural rubber was verified. The Mechanical properties of the rubber products were investigated, tensile strength, tear strength, elongation and load at break was lower than the commercial silica filler. This was due to the lower surface area, large particle size of RHA which results in poor dispersion. In contrary modulus, hardness and abrasion resistance, were superior in the RHAS rubber composites, this due to a better surface activity/reactivity (rubber-filler interaction), the higher silica content in the ash, higher rigidity of the RHAS filler, lower filler-filler interaction and higher filler-rubber matrix interaction, this is because a better presence of Silone functional group in the RHAS surface.

By adding RHAS filler into rubber composites, it can increase properties of, modulus, hardness and abrasion resistance, it could also able to improve the rheological property, most importantly RHAS filled rubber composite minimize the time required to start the vulcanization. However, it was noted from the mechanical and rheological test results, the difference was not considerably significant, thus rice husk silica can be used as renewable filler in natural rubber compounding as replacement filler.

\section{References}

[1] Integrated Pollution Prevention and Control, Reference Document on Best Available Techniques for the Manufacture of Large Volume Inorganic Chemicals - Solids and Other Industry, 2006, European Commission.

[2] Tires and passenger vehicle fuel economy: informing consumers, improving performance /Committee for the National Tire Efficiency Study, Transportation Research Board of the National Academies, Washington, D. C. 2006.

[3] Africarice, A. R. C., Improving Access to Rice Seed and Building a Rice Data System for Sub - Saharan Africa: Final Report of the Japan Emergency Project, J. E. Project, Editor 2010: Cotonou, Benin.

[4] National Rice Development Strategy of Ethiopia, April 13 - 17, 2009: Kampala Uganda.

[5] W. T. Tsai, M. K. Lee, Y. M. Chang, "Fast pyrolysis of rice husk: Product yields and compositions," Bioresource Technology, Vol. 98, pp. 22-28, January 2007.

[6] M. Patel, A. Karera, P. Prasanna "Effect of thermal and chemical treatments on carbon and silica contents in rice husk," Journal of Materials Science, Vol. 22, pp. 2457-2464, July 1987.

[7] Kamath, S. R., Proctor, A. "Silica gel from rice hull ash: preparation and characterization," Cereal Chemistry, Vol.75, pp. $484 \pm 487,1998$. 
[8] Mehta, P. K. "Rice husk ash-a unique supplementary cementing material," Proceedings of the International Symposium on Advances in Concrete Technology, CANMET/ACI, Athens, Greece, pp. 407-430, 1992

[9] Midhun Dominic C. D, P. M Sabura Begum, Rani Joseph, Daisy Joseph, Prabith Kumar and Ayswarya E. P "Synthesis, characterization and appilcation of ricehusk nanosilica in natural rubber," International Journal of Science, Environment and Technology, Vol. 2, pp.1027-1035, 2013.

[10] V. P. Della, I. Kuhn, D. Hotza "Rice husk ash as an alternate source for active silica production," Materials Letters, Vol. 57, pp. 818 - 821, December 2002.

[11] V. R. Shelke, S. S. Bhagade, S. A. Mandavgane "Mesoporous Silica from Rice Husk Ash," Bulletin of Chemical Reaction Engineering and Catalysis, Vol. 5 (2), pp. 63-67, 2010.

[12] Ismail $\mathrm{H}$ and Mega $\mathrm{L}$, "the effects of a compatibilizer and a silane coupling agent on the mechanical properties of white rice husk ash filled polypropylene/natural rubber blend,"
Polymer-Plastics Technology and Engineering, Vol. 40 (4), pp. 463-478, 2001.

[13] Sae-Oui, P., Rakdee, C. \& Thanmathorn, "Use of rice husk ash as filler in natural rubber vulcanizates: In comparison with other commercial fillers," Journal of Applied Polymer Science, Vol.83, pp. 2485-2493, 2002.

[14] Pallavi Tiwari, Sanjay Choudhary, Manish Choudhary, "Study on Mechanical, Thermal and Morphological Properties of RHA Filled PVC Composite," International Journal of Scientific Engineering and Applied Science (IJSEAS), Volume-1 (5), August 2015.

[15] Nithi-uthai, P., "Chemicals for Rubber," Faculty of Science, Prince Songkla University, 1981.

[16] C. Pattamaprom, K. Bandidchutikun, S. Sotananan and S. Phrommedetch, "The effect of rubber modification on physical properties of rice husk ash composites," Thammasat Int. J. Sc. Technol., Vol. 13, pp.36-43, 2008. 